\title{
Donor killer immunoglobulin-like receptor genes and reactivation of cytomegalovirus after HLA-matched hematopoietic stem-cell transplantation: HLA-C allotype is an essential cofactor
}

\author{
Carolyn E. Behrendt ${ }^{1}{ }^{*}$, Ryotaro Nakamura ${ }^{2}$, Stephen J. Forman ${ }^{2}$ and John A. Zaia ${ }^{3}$ \\ 1 Division of Biostatistics and Epidemiology, City of Hope, Duarte, CA, USA \\ 2 Department of Hematology and Hematopoietic Cell Transplantation, City of Hope, Duarte, CA, USA \\ ${ }^{3}$ Department of Virology, Beckman Research Institute of the City of Hope, Duarte, CA, USA
}

\section{Edited by:}

Lewis L. Lanier, University of

California San Francisco, USA

\section{Reviewed by:}

Hugh Reyburn, Spanish National

Research Council, Spain

Jeffrey S. Miller, University of

Minnesota, USA

Karl-Johan Malmberg, Oslo University

Hospital, Norway

\section{${ }^{*}$ Correspondence:}

Carolyn E. Behrendt, Division of Biostatistics and Epidemiology, City of Hope, 1500 East Duarte Road, Duarte, CA 91010, USA.

e-mail: cbehrendt@coh.org
Natural killer (NK) cells whose killer immunoglobulin-like receptors (KIRs) recognize human leukocyte antigen (HLA) ligand are "licensed" for activity. In contrast, nonlicensed NK cells display KIRs for which ligand is absent from the self genotype and are usually hyporesponsive. Surprisingly, non-licensed cells are active in tumor control after hematopoietic stem-cell transplantation (HSCT) and dominate NK response to murine cytomegalovirus (CMV) infection. From those reports, we hypothesized that control of human CMV early after HSCT is influenced by donor KIR genes whose HLA ligand is absent-from-genotype of HLA-matched donor and recipient. To investigate, we studied CMV reactivation through Day 100 after grafts involving CMV-seropositive donor and/or recipient. A multivariate proportional rates model controlled for variability in surveillance and established covariates including acute graft-versus-host disease; statistical significance was adjusted for testing of multiple KIRs with identified HLA class I ligand $(2 D L 1,2 D L 2 / 3$, $2 D S 1,2 D S 2$, full-length 2DS4, 3DL1/3DS1, 3DL2). Among HSCT recipients ( $n=286)$, CMV reactivation-free survival time varied with individual donor KIR genes evolutionarily specific for HLA-C: when ligand was absent from the donor/recipient genotype, inhibitory KIRs $2 D L 2(P<0.0001)$ and $2 D L 1(P=0.015)$ each predicted inferior outcome, and activating KIRs 2DS2 $(P<0.0001), 2 D S 1(P=0.016)$, and 2DS4 $(P=0.016)$ each predicted superior outcome. Otherwise, with ligand present-in-genotype, donor KIR genes had no effect. In conclusion, early after HLA-matched HSCT, individual inhibitory and activating KIR genes have qualitatively different effects on risk of CMV reactivation; unexpectedly, absence of HLA-C ligand from the donor/recipient genotype constitutes an essential cofactor in these associations. Being KIR- and HLA-C-specific, these findings are independent of licensing via alternate NK cell receptors (NKG2A, NKG2C) that recognize HLA-E.

Keywords: cytomegalovirus, hematopoietic stem-cell transplantation, HLA, killer Ig-like receptors, natural killer cells

\section{INTRODUCTION}

Early after hematopoietic stem-cell transplantation (HSCT), the repertoire of natural killer (NK) cells in the recipient is less differentiated than in the donor, skewed toward expression of inhibitory receptor CD94-NKG2A and against expression of killer immunoglobulin-like receptors (KIR; Bjørklund et al., 2010). Within 8-12 weeks after HSCT, however, the proportion of KIR+ NK cells gradually normalizes through cell differentiation, and the responsiveness of KIR + cells comes to depend on the presence of corresponding human leukocyte antigen (HLA) ligand (Haas et al., 2011). NK cell expansions in response to cytomegalovirus (CMV, either latent in the recipient or reactivated) preferentially express activating receptor NKG2C- and HLA-C-specific KIRs that have ligand present-in-genotype (Kuijpers et al., 2008; Della Chiesa et al., 2012; Foley et al., 2012a,b).

Under the tenets of NK cell licensing, those NK cells that express inhibitory KIRs specific for self HLA ligands are functionally competent ("licensed"; Orr and Lanier, 2010). Recent evidence indicates that licensing also applies to NK cells that express activating KIRs (Fauriat et al., 2010). Non-licensed NK cells, on the other hand, express inhibitory KIRs specific for HLA ligands that are absent from the self genotype. Typically, these non-licensed cells are hyporesponsive. Yet, early after HSCT, non-licensed NK cells are clinically beneficial: KIR ligand absent-from-genotype has been associated with lower incidence of leukemic relapse after HLA-matched HSCT (Hsu et al., 2005, 2006; Clausen et al., 2007; Miller et al., 2007) and with better progression-free survival after autologous HSCT for advanced neuroblastoma (Venstrom et al., 2009). According to a recent report (Orr et al., 2010), non-licensed cells dominate the NK response to murine CMV.

These published reports of NK cell functionality in the absence of HLA ligand raise the question of whether control of human CMV following HSCT can be mediated by donor KIRs whose ligand is absent-from-genotype shared by HLA-matched donor 
and recipient. To test this possibility, we prospectively followed HSCT recipients of grafts involving CMV-seropositive donor or recipient. Previous studies of the role of KIRs in controlling human CMV infection have mostly ignored the corresponding HLA ligands (Chen et al., 2006; Cook et al., 2006; Zaia et al., 2009; Gallez-Hawkins et al., 2011; Stern et al., 2011) or have studied the absence of ligand for an aggregate group of inhibitory or activating KIRs (Hadaya et al., 2008; Stern et al., 2008). In contrast, our study evaluated interactions between individual donor KIR genes and the presence or absence of ligand genes in the donor/recipient genotype, as risk factors for CMV reactivation through Day 100 after transplantation. Our analysis adjusted for the testing of multiple hypotheses and took into account established covariates, including method of CMV surveillance (Boeckh et al., 1997), serologic status of donor and recipient (Ljungman et al., 2010), onset of acute graft-versus-host disease (GVHD; Meyers et al., 1986; Bacigalupo et al., 1995; Takenaka et al., 1997; Osarogiagbon etal., 2000; Yanada etal., 2003; Walker etal., 2007; Zaia et al., 2009), use of sirolimus-based regimens for GVHD prophylaxis (Marty et al., 2007), and source of stem-cell graft (Guerrero et al., 2012).

\section{MATERIALS AND METHODS ETHICS STATEMENT}

The protocol for this observational cohort study was approved in advance by the hospital's institutional review board. Before undergoing HSCT, all subjects gave written informed consent to prospective follow-up and periodic blood sampling.

\section{SUBJECTS}

Eligible subjects were consecutive patients age 18 or older who underwent a first HLA-matched, allogeneic HSCT in 2000-2006 for underlying hematologic disease, receiving a graft of unmanipulated stem-cells from the peripheral blood or bone marrow of a non-syngeneic sibling or unrelated donor. Further, only those transplants in which donor and/or recipient was CMVseropositive prior to transplant were eligible for study. Exclusion criteria for the current analysis were incomplete data [on donor CMV serostatus ( $n=5)$ or KIR genotype $(n=5)$ ] or lack of standard CMV surveillance (due to reactivation detected immediately before transplantation or other reason $[n=5])$. CMV prophylaxis was not utilized, but preemptive treatment with ganciclovir was started upon detection of CMV reactivation in blood as previously described (Zaia et al., 2009).

\section{TYPING OF HLA AND KIR}

Human leukocyte antigen typing of donors and recipients was performed using one or more of the following methods: microbead array assay with sequence-specific oligonucleotide probes (One Lambda, Canoga Park, CA, USA), polymerase chain reaction (PCR) amplification with sequence-specific primers (Olerup SSP $\mathrm{AB}$, Saltsjöbaden, Sweden; Invitrogen Corporation, Carlsbad, CA, USA), and sequence-based typing (Celera Corporation, Alameda, CA, USA). HLA-C allotypes belong to two groups distinguished by the amino acid residue at position 80 ; those allotypes with an asparagine are termed group 1 or $C 1$, and those with a lysine are termed group 2 or C2 (Vilches and Parham, 2002).
For KIR typing, a previously described method (Sun et al., 2004) was used to identify the functional, non-framework KIR genes (2DS1-5; 3DS1; 2DL1-3 and 2DL5; 3DL1) and distinguish full-length from deleted alleles of KIR2DS4 (Parham, 2005).

\section{SURVEILLANCE FOR CMV REACTIVATION}

At physician discretion, surveillance for CMV usually began as close as possible to post-transplant Day 21 and generally continued until post-transplant Day 80-100. For surveillance, blood was collected once or twice-weekly and assayed by shell vial culture of whole blood (Gleaves et al., 1985). Whenever possible, plasma from the same specimen was assayed by DNA-quantitative PCR, limit of CMV detection: 200 genome copies/mL (Gallez-Hawkins et al., 2005). As clinically indicated, bronchoalveolar lavage and tissue biopsies were also tested for CMV by histopathology or tissue culture. The day of CMV reactivation was defined as the earliest positive result by any of these methods.

\section{STATISTICAL METHODS}

The study endpoint was survival time free of CMV reactivation by Day 100 after HSCT. Follow-up was censored when Day 100 posttransplantation was reached or when CMV surveillance ended earlier. In addition, cumulative incidences of CMV reactivation and death without CMV were calculated as separate, competing events (Fine and Gray, 1999).

Because use of PCR and frequency of testing could vary during surveillance, it was necessary to consider each subject's surveillance as one or more periods, with a new period being started whenever the conditions of surveillance changed, from twice-weekly to once per week or from testing by PCR and viral culture to testing by culture alone. To ensure that surveillance would be at least 1 day in duration even when CMV was detected in the subject's first specimen, each surveillance period began on the eve of the first assay performed during that period. Multivariate analysis employed a proportional rates model of time to CMV reactivation or death; a robust sandwich covariance estimate took into account the intracluster dependence arising when there were multiple observations per subject (Lin et al., 2000).

The primary risk factors included the seven donor KIR genes with an identified HLA ligand: KIR2DL1, KIR2DL2, KIR2DS1, KIR2DS2, KIR2DS4, KIR3DS1, and universally present KIR3DL2. Each KIR gene was analyzed as: present with its evolutionarily specific ligand "present-in-genotype," present with ligand "absentfrom-genotype," and KIR gene absent. For those KIRs that belong to pairs of alleles (2DL2/2DL3 and $3 D L 1 / 3 D S 1)$, one allele from each pair was selected for the multivariate analysis; no association was observed with the non-selected alleles when these were included also. Because of biological evidence of delayed expression of KIR2DL1 (Fischer et al., 2007), the analysis considered whether associations with this KIR and with its homolog, KIR2DS1, were time-dependent. To do so, we considered delays of $0-8$ weeks between day of transplantation and expression of these two KIRs; for each KIR, the delay with the best fit to the observed data was retained in the model. In order to limit the study's overall Type I error rate to $5 \%, P$ values for the primary risk factors were adjusted for multiple hypothesis testing using Holm's method, a more powerful version of the Bonferroni test (Holm, 1979). 
The model was adjusted for potentially confounding timedependent variables (onset of acute GVHD that ultimately reached grade II-IV (Przepiorka et al., 1995); twice-weekly versus onceweekly surveillance) and fixed covariates (donor's CMV serostatus and sibling versus unrelated status; female-to-male graft; source of stem-cells; specific underlying disease; use of sirolimus for GVHD prophylaxis; year of transplantation). Additional factors considered in the model were the recipient's CMV serostatus and age at transplantation, as well as donor KIR genes that have no identified HLA class I ligand (2DS3, 2DS5, 2DL5). Because hematologic diagnosis correlated so closely with intensity of conditioning regimen and disease status at transplantation, the latter two variables were dropped from multivariate analysis.

The assumption of proportionality of rates over time was verified by examining Schoenfeld residuals generated by the model. The fit of the model to individual subjects was assessed by examining dfbeta (weighted transformation of the score residual, approximating the change in a covariate's effect when a given observation is omitted).

\section{RESULTS}

\section{SUBJECTS}

The cohort included 286 subjects [age 43.0(11.6) years] who underwent HLA-matched, allogeneic HSCT in which donor and/or recipient was CMV-seropositive (Table 1). Acute GVHD grade II-IV developed before or during follow-up in 154 (53.8\%) subjects and was already present at start of surveillance in 70 (24.5\%) subjects.

Donor's KIR genes, classified by presence or absence of HLA ligand when applicable, are shown in Table 2. Being in linkage disequilibrium, donor KIR2DL2 and KIR2DS2 were almost always present together, but occasionally one or the other gene appeared alone: 123 subjects had donors with KIR2DL2, of whom 120 had donor KIR2DS2 also, and 123 subjects had donors with KIR2DS2, of whom 120 had donor KIR2DL2 also.

\section{SURVEILLANCE FOR CMV REACTIVATION}

In nearly all (90.6\%) subjects, surveillance began within the 7 days before or after Day 21 post-transplantation. Usually, surveillance was performed twice per week and utilized both viral culture and DNA-quantitative PCR. However, in $28.7 \%$ of subjects, at least some surveillance was by culture alone, and in $15.4 \%$ of subjects, at least some surveillance was once per week.

At the close of surveillance by Day 100 post-transplantation, cumulative incidences (standard deviation) of CMV reactivation and of death not preceded by CMV disease or reactivation were 66.4(3.0) and 3.0(1.0)\%, respectively. There were seven cases of CMV disease [gastritis $(n=3)$, colitis $(n=2)$, or pneumonitis $(n=2)]$, none of which contributed to a death. Instead, deaths without prior CMV activity $(n=8)$ were attributed to acute respiratory distress syndrome and/or multi-organ system failure $(n=5)$, relapsed or progressive leukemia $(n=2)$, and venoocclusive disease of the liver $(n=1)$. Of subjects $(n=96)$ who did not experience CMV reactivation or death, nearly all $(86.5 \%)$ continued surveillance through at least Day 80 post-HSCT.

Because cases of CMV reactivation so thoroughly outnumbered deaths without prior reactivation (by a ratio of 182:8), the analysis
Table 1 | Characteristics of HSCT recipients and grafts $(N=286)$

\begin{tabular}{ll}
\hline RECIPIENT & $N(\%)$ \\
\hline
\end{tabular}

Year of age at transplantation

18-39

$103(36.0)$

40-59

$160(55.9)$

60-68

$23(8.0)$

Hematologic diagnosis

Leukemia

209 (73.1)

Acute lymphoid leukemia

53 (18.5)

Acute myeloid leukemia

91 (31.8)

Chronic lymphoid leukemia

3 (1.1)

Chronic myeloid leukemia

$41(14.3)$

Myelodysplastic syndrome

21 (7.3)

Other

$77(26.9)$

Hodgkin lymphoma

$6 \quad(2.1)$

Multiple myeloma

4 (1.4)

Myeloproliferative disorder

7 (2.5)

Non-Hodgkin lymphoma

$49(17.1)$

Severe aplastic anemia

11 (3.9)

Calendar year of transplantation

2000-2002

104 (36.4)

2003-2006

$182(63.6)$

Prophylaxis for graft-versus-host disease

Sirolimus and tacrolimus

$50(17.5)$

Tacrolimus and methotrexate

$66(23.1)$

Mycophenolate mofetil-based regimen

95 (33.2)

Cyclosporin A and methotrexate

$75(26.2)$

\section{GRAFT}

Donor type

Sibling

$184(64.3)$

Unrelated

$102(35.7)$

Source of graft

Peripheral blood

239 (83.6)

Bone marrow

47 (16.4)

Sex of donor, recipient

$D$ female, $R$ male

$58(20.3)$

$D$ female, $R$ female

$57(19.9)$

$D$ male, $R$ male

$96(33.6)$

$D$ male, $R$ female

$75(26.2)$

Pretransplant CMV serostatus of donor, recipient

$\begin{array}{lr}D_{-}, \mathrm{R}+ & 76(26.6) \\ \mathrm{D}+, \mathrm{R}- & 29(10.1) \\ \mathrm{D}+, \mathrm{R}+ & 181(63.3)\end{array}$

CMV, cytomegalovirus; D, donor; HSCT, hematopoietic stem-cell transplant; $R$, recipient. 
Table 2 | Donor KIR genes, by presence of HLA ligand in shared genotype of donor and recipient pair $(N=286)$.

\begin{tabular}{|c|c|}
\hline & $N(\%)$ \\
\hline \multicolumn{2}{|l|}{ Inhibitory KIR } \\
\hline \multicolumn{2}{|l|}{$2 D L 1$} \\
\hline With C2 & $162(56.7)$ \\
\hline Without $C 2$ & 114 (39.9) \\
\hline No donor KIR2DL1 & 10 \\
\hline \multicolumn{2}{|l|}{$2 D L 2$} \\
\hline With $C 1$ & $103(36.0)$ \\
\hline Without $C 1$ & $20 \quad(7.0)$ \\
\hline No donor $K I R 2 D L 2$ & $163(57.0)$ \\
\hline \multicolumn{2}{|l|}{$2 D L 3$} \\
\hline With C1 & $225(78.7)$ \\
\hline Without $C 1$ & 38 (13.3) \\
\hline No donor KIR2DL3 & $23(8.0)$ \\
\hline \multicolumn{2}{|l|}{$2 D L 5$} \\
\hline Present & $138(48.3)$ \\
\hline Absent & $148(51.7)$ \\
\hline \multicolumn{2}{|l|}{$3 D L 1$} \\
\hline With $B-B w 4$ & $152(53.2)$ \\
\hline Without $B-B w 4$ & $118(41.3)$ \\
\hline No donor KIR3DL1 & $16 \quad(5.6)$ \\
\hline \multicolumn{2}{|l|}{$3 D L 2$ (universally present) } \\
\hline With $A-3$ and/or $A-11$ & $95(33.2)$ \\
\hline Without $A-3$ and/or $A-11$ & $191(66.8)$ \\
\hline \multicolumn{2}{|l|}{ Activating KIR } \\
\hline \multicolumn{2}{|l|}{$2 D S 1$} \\
\hline With C2 & $61(21.3)$ \\
\hline Without $C 2$ & $43(15.0)$ \\
\hline No donor KIR2DS1 & $182(63.6)$ \\
\hline \multicolumn{2}{|l|}{$2 D S 2$} \\
\hline With C1 & $105(36.7)$ \\
\hline Without $C 1$ & $18 \quad(6.3)$ \\
\hline No donor KIR2DS2 & $163(57.0)$ \\
\hline \multicolumn{2}{|l|}{$2 D S 3$} \\
\hline Present & $75(26.2)$ \\
\hline Absent & $211(73.8)$ \\
\hline \multicolumn{2}{|l|}{ 2DS4 (full-length allele) } \\
\hline With $C^{*} 0501, C^{*} 1601$ & 10 \\
\hline Without $C^{*} 0501$ or $C^{*} 1601$ & $121(42.3)$ \\
\hline No donor KIR2DS4 (full-length allele) & $155(54.2)$ \\
\hline \multicolumn{2}{|l|}{$2 D S 5$} \\
\hline Present & $81(28.3)$ \\
\hline Absent & $205(71.7)$ \\
\hline \multicolumn{2}{|l|}{$3 D S 1$} \\
\hline With $B-B w 4$ & $61(21.3)$ \\
\hline Without $B-B w 4$ & $46(16.1)$ \\
\hline No donor KIR3DS1 & $179(62.6)$ \\
\hline
\end{tabular}

of CMV reactivation-free survival closely approximated an analysis of time to CMV reactivation. Moreover, had the eight subjects who died without CMV reactivation been omitted from analysis, the results would have been virtually unchanged (data not shown).

\section{GENETIC ASSOCIATIONS WITH CMV REACTIVATION}

In multivariate analysis (Table 3), five of the seven KIRs studied were associated with CMV reactivation, as follows. Inhibitory KIR2DL2 and KIR2DL1 were independently associated with increased likelihood of CMV reactivation, but only when the corresponding ligand was absent from the genotype shared by donor and recipient. Of note, the association with KIR2DL2 was more marked and began earlier than the association with KIR2DL1, which did not begin until Day 49 post-HSCT. Likewise, activating KIR2DS2, KIR2DS1, and KIR2DS4 (full-length allele) were each associated with reduced likelihood of reactivation, but only when the corresponding ligand was absent from the genotype. Of note, the association with KIR2DS2 was more marked and began earlier than the association with KIR2DS1, which did not begin until Day 21. The protection against CMV reactivation associated with KIR2DS4 (full-length allele), although significant, was less marked than that associated with KIR2DS2 and KIR2DS1.

Donor KIR genes without identified HLA class I ligand (KIR2DS3, KIR2DS5, KIR2DL5) did not contribute to the fit of the model and were therefore omitted. When the model was limited to the primary risk factors, adjusted only for whether surveillance for CMV included PCR, the results were similar (data not shown). Whether a KIR's ligand was present in one or two gene copies did not alter any of the associations (data not shown).

\section{DISCUSSION}

According to this study, the risk of CMV reactivation following HLA-matched HSCT is associated with individual donor KIR genes, but only when their evolutionarily specific HLA-C ligand is absent from the shared donor/recipient genotype. Our results add to the evidence that non-licensed NK cells can play an important role in host control of tumors (Hsu et al., 2005, 2006; Clausen et al., 2007; Miller et al., 2007; Venstrom et al., 2009) and infection, specifically murine CMV (Orr et al., 2010), with one important difference. Unlike previous reports, our study suggests that "presumably non-licensed" NK cells (inhibitory KIRs with ligand absent-from-genotype) are associated with worse, not better, clinical outcome, while comparable activating KIRs (those with ligand absent-from-genotype) have qualitatively opposite effects, being associated with better, not worse, clinical outcome among our subjects. Also, unlike studies in vitro (Kim et al., 2008; Fauriat et al., 2010), our clinical study did not detect a dose effect from the gene copy number of HLA ligand.

The chief limitation of our study is the lack of in vitro data, on $\mathrm{KIR}$ expression in NK and $\mathrm{T}$ cells and on the licensing status of KIR-bearing cells early after allogeneic HSCT. Conclusions can still be drawn from these genotyping data, because a ligand absent-ingenotype can be expected to be absent in expression also. Although unstudied here, expression of NKG2A and NKG2C could not have confounded our results: because our findings are KIR- and HLA$\mathrm{C}$-specific, they are independent of licensing through NKG2A or NKG2C, which recognize HLA-E. 
Table 3 | CMV reactivation-free survival after HLA-matched, allogeneic HSCT ( $N=286$ ).

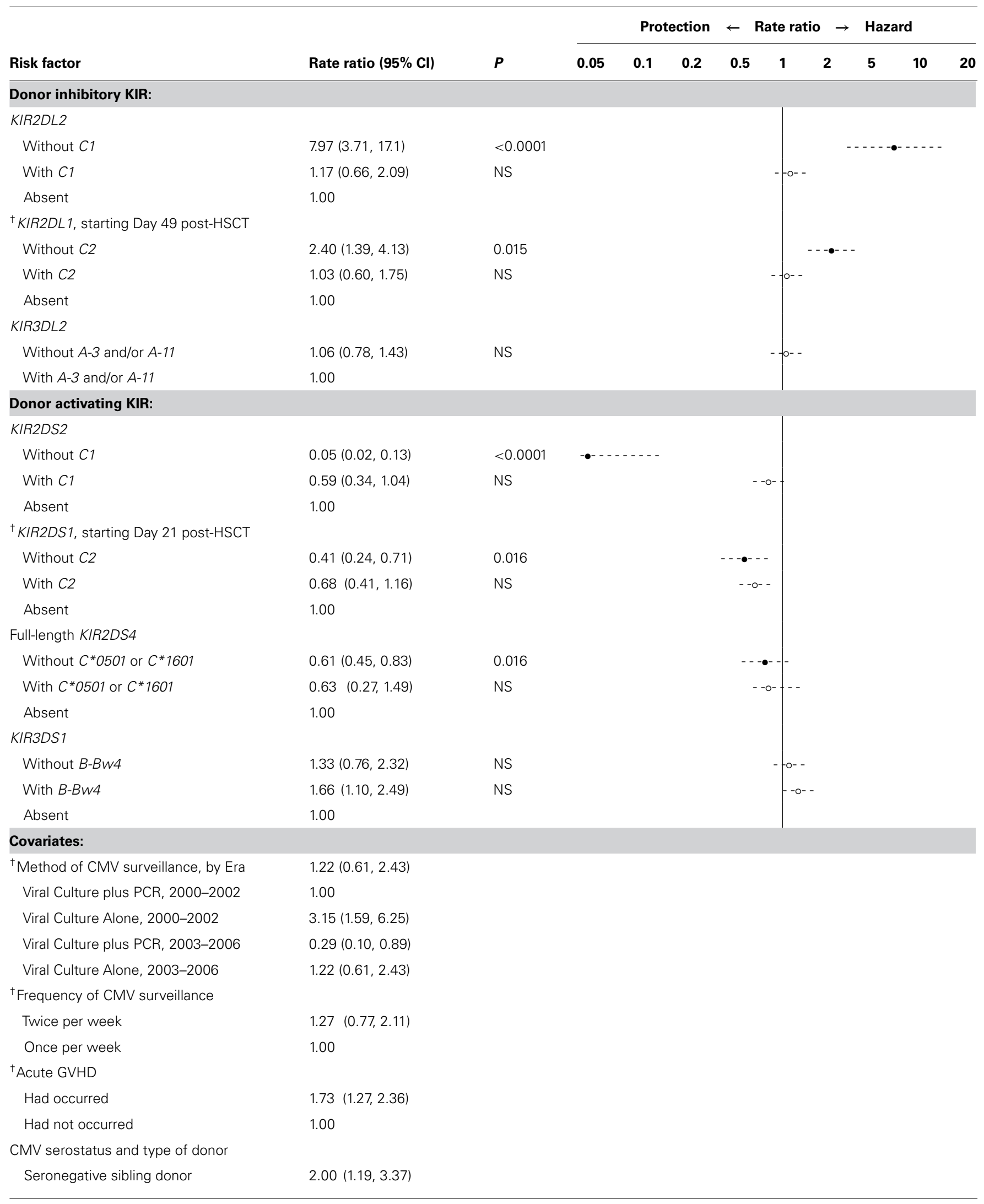




\begin{tabular}{|c|c|c|c|c|c|c|c|c|c|c|c|}
\hline \multirow[b]{2}{*}{ Risk factor } & \multirow[b]{2}{*}{ Rate ratio $(95 \% \mathrm{CI})$} & \multirow[b]{2}{*}{$P$} & \multicolumn{3}{|c|}{ Protection } & $\leftarrow$ & \multicolumn{2}{|c|}{ Rate ratio } & \multicolumn{2}{|c|}{ Hazard } & \multirow[b]{2}{*}{20} \\
\hline & & & 0.05 & 0.1 & 0.2 & 0.5 & 1 & 2 & 5 & 10 & \\
\hline Seronegative unrelated donor & $0.99(0.66,1.48)$ & & & & & & & & & & \\
\hline Seropositive unrelated donor & $1.07(0.74,1.57)$ & & & & & & & & & & \\
\hline \multicolumn{12}{|l|}{ GVHD prophylaxis } \\
\hline Other regimen & 1.00 & & & & & & & & & & \\
\hline \multicolumn{12}{|l|}{ Female-to-male graft } \\
\hline Yes & $1.34(0.93,1.92)$ & & & & & & & & & & \\
\hline No & 1.00 & & & & & & & & & & \\
\hline \multicolumn{12}{|c|}{ Leukemia/myelodysplastic syndrome } \\
\hline Bone marrow & $0.72(0.47,1.11)$ & & & & & & & & & & \\
\hline Peripheral blood & 1.00 & & & & & & & & & & \\
\hline
\end{tabular}

Solid circles illustrate statistically significant associations, while open circles illustrate non-significant ones.

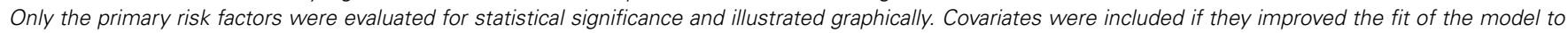
the data. P values were corrected for multiple hypothesis testing using the Holm-Bonferroni adjustment (Holm, 1979).

' Covariate's effect is time-dependent, due to a change in a subject's surveillance or to delayed onset of the risk factor.

The current study is not the first to associate the control of human CMV with KIRs that are evolutionarily specific for HLAC (Kuijpers et al., 2008; Foley et al., 2012a,b). Such KIRs present a number of special considerations. For instance, KIR2DL2 and KIR2DS2 are in linkage disequilibrium; as a result, our sample included few donors having one of these genes but not the other ("discordant donors," $n=6$ ). Nevertheless, associations with each of these two KIRs were so strong that they could be detected in our sample. Current findings do not depend on the six subjects with discordant donor, however. When those subjects are omitted, the model still shows that, relative to having neither KIR2DL2 nor KIR2DS2, having both donor genes with ligand absent-from-genotype is associated with a 0.4 -fold reduction in risk of reactivation, a figure that corresponds, as it should do, to the product of the associations we report in Table 3 for KIR2DL2 without C1 (7.97) and KIR2DS2 without C1 (0.05). In other words, in the absence of ligand, the combined effects of inhibitory KIR2DL2 and activating KIR2DS2 result in a net reduction in CMV reactivation, the 20 -fold reduction in risk associated with KIR2DS2 (rate ratio 0.05 ) outweighing the eightfold increase in risk associated with KIR2DL2. Thus, despite their partial homology, inhibitory KIR2DL2 and activating KIR2DS2 have qualitatively different effects on risk of CMV reactivation, as KIR2DL1 and KIR2DS1 currently do also.

KIR2DS2 has reportedly lost avidity for its evolutionary ligand, C1 (Moesta et al., 2010). Nevertheless, in the current study (Table 3), $\mathrm{Cl}$ in genotype eliminated the benefit associated with KIR2DS2 just as it eliminated the disadvantage associated with KIR2DL2. Our genotypic data cannot reveal the mechanism underlying this apparent $\mathrm{KIR} 2 \mathrm{DS} 2-\mathrm{C} 1$ interaction, but the finding suggests that, at least in the setting of CMV infection after HSCT, binding affinity of KIR2DS2 for C1 may be present in vivo, perhaps facilitated by a peptide of viral origin. C1-specific KIRs (KIR2DL2, KIR2DL3) reportedly recognize a few $C 2$ alleles also, most strongly $C^{\star} 0501$ (Graef et al., 2009). If the latter allele is included as a ligand for KIR2DL2 (and for its partial homolog, KIR2DS2), the results of the current study are virtually unchanged (data not shown). In addition, KIR2DS4 recognizes more than one ligand, chiefly a $C 2$ allele $\left(C^{\star} 0501\right)$, a $C 1$ allele $\left(C^{\star} 1601\right)$, and $A^{\star} 1102$ (an allele not present among our sample; Graef et al., 2009). In our study, because the latter three ligands are uncommon, KIR2DS4 was nearly always present without ligand-in-genotype, potentially explaining a previously reported association between KIR2DS4 and reduced risk of CMV reactivation after HSCT (Chen et al., 2006; Cook et al., 2006; Zaia etal., 2009; Gallez-Hawkins et al., 2011; Stern et al., 2011).

Because KIR2DL2 and KIR2DL3 are alleles, it is possible for one or both alleles to be present in a given donor. In our analysis, the association with donor KIR2DL2 was unaffected by whether KIR2DL3 was also present (data not shown), a finding consistent with reports that KIR2DL2 is a stronger receptor for ligand C1 than is KIR2DL3 (Moesta et al., 2008, 2010; Fadda et al., 2010). Furthermore, during NK cell development from progenitor cells, KIR2DL1 appears later and at lower frequency than KIR2DL2 and KIR2DL3, which dominate the early NK cell repertoire (Fischer et al., 2007). Accordingly, current associations of CMV reactivation with KIR2DL1 and its partial homolog, KIR2DS1, were qualitatively similar to, but with later onset and lower magnitude than, the associations of their non-time-dependent counterparts, KIR2DL2 and KIR2DS2. 
Under the arming model (Raulet and Vance, 2006), NK cells are hyporesponsive by default and become responsive upon interaction between inhibitory KIR and ligand. In contrast, under the disarming model (Raulet and Vance, 2006), NK cells are responsive by default and become hyporesponsive from lack of interaction between inhibitory KIR and ligand. Our own observations are more consistent with the latter model, with the difference that, in our study, disarming applies to activating as well as inhibitory KIRs, which in turn exert qualitatively different effects on control of CMV after HLA-matched HSCT. Specifically, inhibitory KIR without HLA interaction results in inferior outcome (greater incidence of CMV reactivation), while activating KIR without HLA interaction results in superior outcome (lower incidence of reactivation) among our subjects.

Taken together, our observations suggest that, at least in the first 100 days after HLA-matched HSCT, the HLA ligand, rather than providing a license for function, serves as a gatekeeper of inherent

\section{REFERENCES}

Bacigalupo, A., Tedone, E., Isaza, A., Soracco, M., Van Lint, M. T., Sanna, A., etal. (1995). CMVantigenemia after allogeneic bone marrow transplantation: correlation of CMV-antigen positive cell numbers with transplant-related mortality. Bone Marrow Transplant. 16, 155-161.

Bjørklund, A. T., Schaffer, M., Fauriat, C., Ringden, O., Remberger, M., Hammarstedt, C., et al. (2010). NK cells expressing inhibitory KIR for non-self-ligands remain tolerant in HLA-matched sibling stem cell transplantation. Blood 115, 26862694.

Boeckh, M., Gallez-Hawkins, G. M., Myerson, D., Zaia, J. A., and Bowden, R. A. (1997). Plasma polymerase chain reaction for cytomegalovirus DNA after allogeneic marrow transplantation: comparison with polymerase chain reaction using peripheral blood leukocytes, pp65 antigenemia, and viral culture. Transplantation 64, 108-113.

Chen, C., Busson, M., Rocha, V., Appert, M. L., Lepage, V., Dulphy, N., et al. (2006). Activating KIR genes are associated with CMV reactivation and survival after non-T-cell depleted HLA-identical sibling bone marrow transplantation for malignant disorders. Bone Marrow Transplant. 38, 437-444.

Clausen, J., Wolf, D., Petzer, A. L., Gunsilius, E., Schumacher, P., Kircher, B., etal. (2007). Impact of natural killer cell dose and donor killercell immunoglobulin-like receptor (KIR) genotype on outcome following human leucocyte antigenidentical haematopoietic stem cell transplantation. Clin. Exp. Immunol. $148,520-528$.
Cook, M., Briggs, D., Craddock, C., Mahendra, P., Milligan, D., Fegan, C., et al. (2006). Donor KIR genotype has a major influence on the rate of cytomegalovirus reactivation following T-cell replete stem cell transplantation. Blood 107, 1230-1232.

Della Chiesa, M., Falco, M., Podesta, M., Locatelli, F., Moretta, L., Frassoni, F., et al. (2012). Phenotypic and functional heterogeneity of human NK cells developing after umbilical cord blood transplantation: a role for human cytomegalovirus? Blood 119, 399-410.

Fadda, L., Borhis, G., Ahmed, P., Cheent, K., Pageon, S. V., Cazaly, A., et al. (2010). Peptide antagonism as a mechanism for NK cell activation. Proc. Natl. Acad. Sci. U.S.A. 107, 10160-10165.

Fauriat, C., Ivarsson, M. A., Ljunggren, H. G., Malmberg, K. J., and Michaelsson, J. (2010). Education of human natural killer cells by activating killer cell immunoglobulin-like receptors. Blood 115, 1166-1174.

Fine, J. P., and Gray, R. J. (1999). A proportional hazards model for the subdistribution of a competing risk. J. Am. Stat. Assoc. 94, 496-509.

Fischer, J. C., Ottinger, H., Ferencik, S., Sribar, M., Punzel, M., Beelen, D. W., etal. (2007). Relevance of $\mathrm{C} 1$ and $\mathrm{C} 2$ epitopes for hemopoietic stem cell transplantation: role for sequential acquisition of HLA-C-specific inhibitory killer Iglike receptor. J. Immunol. 178, 39183923.

Foley, B., Cooley, S., Verneris, M. R., Curtsinger, J., Luo, X., Waller, E. K., et al. (2012a). Human cytomegalovirus (CMV)cells are transplantable and expand in vivo in response to recipient CMV induced memory-like NKG2C+ NK

NK cell activity: with ligand, KIR-mediated activity is held in check, while without ligand, KIR-mediated activity is unrestricted. Moreover, this "gatekeeping" applies to inhibitory and activating KIRs alike, the only difference being that inhibitory KIR's inherent activity is harmful to host control of CMV, while activating KIR's effect is beneficial, apparently promoting viral clearance. It is possible that this gatekeeping concept can be exploited in the development of NK-based cell therapy or in predicting a transplant recipient's risk of CMV reactivation.

\section{ACKNOWLEDGMENTS}

The authors gratefully acknowledge the insightful comments from reviewers. This work was supported by grants from the National Institutes of Health [R01-AI58148, 2R01-CA145207, P01-CA30206, M01-RR00043-38, and P30-CA033572]. This publication is solely the responsibility of the authors and does not necessarily represent the official views of the NIH.

antigen. J. Immunol. 189, 50825088.

Foley, B., Cooley, S., Verneris, M. R., Pitt, M., Curtsinger, J., Luo, X., et al (2012b). Cytomegalovirus reactivation after allogeneic transplantation promotes a lasting increase in educated NKG2C+ natural killer cells with potent function. Blood 119, 2665-2674.

Gallez-Hawkins, G., Thao, L., Lacey, S. F., Martinez, J., Li, X., Franck, A. E., et al. (2005). Cytomegalovirus immune reconstitution occurs in recipients of allogeneic hematopoietic cell transplants irrespective of detectable cytomegalovirus infection. Biol. Blood Marrow Transplant. 11, 890-902.

Gallez-Hawkins, G. M., Franck, A. E., Li, X., Thao, L., Oki, A., Gendzekhadze, K., et al. (2011). Expression of activating KIR2DS2 and KIR2DS4 genes after hematopoietic cell transplantation: relevance to cytomegalovirus infection. Biol. Blood Marrow Transplant. 17, 1662-1672.

Gleaves, C. A., Smith, T. F., Shuster, E. A., and Pearson, G. R. (1985). Comparison of standard tube and shell vial cell culture techniques for the detection of cytomegalovirus in clinical specimens. J. Clin. Microbiol. 21, 217-221.

Graef, T., Moesta, A. K., Norman, P. J., Abi-Rached, L., Vago, L., Older Aguilar, A. M., et al. (2009). KIR2DS4 is a product of gene conversion with KIR3DL2 that introduced specificity for HLA-A* 11 while diminishing avidity for HLA-C. J. Exp. Med. 206, 2557-2572.

Guerrero, A., Riddell, S. R., Storek, J., Stevens-Ayers, T., Storer, B., Zaia, J. A., et al. (2012). Cytomegalovirus viral load and virus-specific immune reconstitution after peripheral blood stem cell versus bone marrow transplantation. Biol. Blood Marrow Transplant. 18, 66-75.

Haas, P., Loiseau, P., Tamouza, R., Cayuela, J. M., Moins-Teisserenc, H., Busson, M., et al. (2011). NK-cell education is shaped by donor HLA genotype after unrelated allogeneic hematopoietic stem cell transplantation. Blood 117, 1021-1029.

Hadaya, K., De Rham, C., Bandelier, C., Ferrari-Lacraz, S., Jendly, S., Berney, T., et al. (2008). Natural killer cell receptor repertoire and their ligands, and the risk of CMV infection after kidney transplantation. Am. J. Transplant. 8, 2674-2683.

Holm, S. (1979). A simple sequentially rejective multiple test procedure. Scand. J. Stat. 6, 65-70.

Hsu, K. C., Gooley, T., Malkki, M., Pinto-Agnello, C., Dupont, B., Bignon, J. D., et al. (2006). KIR ligands and prediction of relapse after unrelated donor hematopoietic cell transplantation for hematologic malignancy. Biol. Blood Marrow Transplant. 12, 828-836.

Hsu, K. C., Keever-Taylor, C. A., Wilton, A., Pinto, C., Heller, G., Arkun, K., et al. (2005). Improved outcome in HLA-identical sibling hematopoietic stem-cell transplantation for acute myelogenous leukemia predicted by KIR and HLA genotypes. Blood 105, 4878-4884.

Kim, S., Sunwoo, J. B., Yang, L., Choi, T., Song, Y. J., French, A. R., et al. (2008). HLA alleles determine differences in human natural killer cell responsiveness and potency. Proc. Natl. Acad. Sci. U.S.A. 105, 30533058.

Kuijpers, T. W., Baars, P. A., Dantin, C., van den Burg, M., van Lier, R. A., and Roosnek, E. (2008). Human NK cells can control CMV infection 
in the absence of T cells. Blood 112, 914-915.

Lin, D. Y., Wei, L. J., Yang, I., and Ying, Z. (2000). Semiparametric regression for the mean and rate functions of recurrent events. J R Stat. Soc. Series B Stat. Methodol. 62, 711-730.

Ljungman, P., Hakki, M., and Boeckh, M. (2010). Cytomegalovirus in hematopoietic stem cell transplant recipients. Infect. Dis. Clin. North Am. 24, 319-337.

Marty, F. M., Bryar, J., Browne, S. K., Schwarzberg, T., Ho, V. T., Bassett, I. V., et al. (2007). Sirolimus-based graft-versus-host disease prophylaxis protects against cytomegalovirus reactivation after allogeneic hematopoietic stem cell transplantation: a cohort analysis. Blood 110, 490-500.

Meyers, J. D., Flournoy, N., and Thomas, E. D. (1986). Risk factors for cytomegalovirus infection after human marrow transplantation. J. Infect. Dis. 153, 478-488.

Miller, J. S., Cooley, S., Parham, P., Farag, S. S., Verneris, M. R., Mcqueen, K. L., et al. (2007). Missing KIR ligands are associated with less relapse and increased graft-versus-host disease (GVHD) following unrelated donor allogeneic HCT. Blood 109, 5058-5061.

Moesta, A. K., Graef, T., Abi-Rached, L., Older Aguilar, A. M., Guethlein, L. A., and Parham, P. (2010). Humans differ from other hominids in lacking an activating NK cell receptor that recognizes the $\mathrm{C} 1$ epitope of MHC class I. J. Immunol. 185, 4233-4237.

Moesta, A. K., Norman, P. J., Yawata, M., Yawata, N., Gleimer, M., and Parham, P. (2008). Synergistic polymorphism at two positions distal to the ligand-binding site makes
KIR2DL2 a stronger receptor for HLA-C than KIR2DL3. J. Immunol. 180, 3969-3979.

Orr, M. T., and Lanier, L. L. (2010). Natural killer cell education and tolerance. Cell 142, 847-856.

Orr, M. T., Murphy, W. J., and Lanier, L. L. (2010). 'Unlicensed' natural killer cells dominate the response to cytomegalovirus infection. Nat. Immunol. 11, 321-327.

Osarogiagbon, R. U., Defor, T. E., Weisdorf, M. A., Erice, A., and Weisdorf, D. J. (2000). CMV antigenemia following bone marrow transplantation: risk factors and outcomes. Biol. Blood Marrow Transplant. 6 , 280-288.

Parham, P. (2005). MHC class I molecules and KIRs in human history, health and survival. Nat. Rev. Immunol. 5, 201-214.

Przepiorka, D., Weisdorf, D., Martin, P., Klingemann, H. G., Beatty, P. Hows, J., etal. (1995). 1994 consensus conference on acute GVHD grading. Bone Marrow Transplant. 15, 825-828.

Raulet, D. H., and Vance, R. E. (2006) Self-tolerance of natural killer cells. Nat. Rev. Immunol. 6, 520-531.

Stern, M., Elsasser, H., Honger, G. Steiger, J., Schaub, S., and Hess, C. (2008). The number of activating KIR genes inversely correlates with the rate of CMV infection/reactivation in kidney transplant recipients. Am. J. Transplant. 8, 1312-1317.

Stern, M., Hadaya, K., Honger, G., Martin, P. Y., Steiger, J., and Hess, C. (2011). Telomeric rather than centromeric activating KIR genes protect from cytomegalovirus infection after kidney transplantation. Am. J. Transplant. 11, 1302-1307.
Sun, J. Y., Gaidulis, L., Miller, M. M., Goto, R. M., Rodriguez, R., Forman, S. J., et al. (2004). Development of a multiplex PCR-SSP method for Killer-cell immunoglobulin-like receptor genotyping. Tissue Antigens 64, 462-468.

Takenaka, K., Gondo, H., Tanimoto, K. Nagafuji, K., Fujisaki, T., Mizuno, S., et al. (1997). Increased incidence of cytomegalovirus (CMV) infection and $\mathrm{CMV}$-associated disease after allogeneic bone marrow transplantation from unrelated donors. The Fukuoka Bone Marrow Transplantation Group. Bone Marrow Transplant. 19, 241-248.

Venstrom, J. M., Zheng, J., Noor, N., Danis, K. E., Yeh, A. W., Cheung, I. Y., et al. (2009). KIR and HLA genotypes are associated with disease progression and survival following autologous hematopoietic stem cell transplantation for high-risk neuroblastoma. Clin. Cancer Res. 15, 7330-7334.

Vilches, C., and Parham, P. (2002). KIR diverse, rapidly evolving receptors of innate and adaptive immunity. Annu. Rev. Immunol. 20, 217-251.

Walker, C. M., Van Burik, J. A., De For, T. E., and Weisdorf, D. J. (2007) Cytomegalovirus infection after allogeneic transplantation: comparison of cord blood with peripheral blood and marrow graft sources. Biol. Blood Marrow Transplant. 13, 1106 1115.

Yanada, M., Yamamoto, K., Emi, N., Naoe, T., Suzuki, R., Taji, H., et al. (2003). Cytomegalovirus antigenemia and outcome of patients treated with pre-emptive ganciclovir: retrospective analysis of 241 consecutive patients undergoing allogeneic hematopoietic stem cell transplantation. Bone Marrow Transplant. 32, 801-807.

Zaia, J. A., Sun, J. Y., Gallez-Hawkins, G. M., Thao, L., Oki, A., Lacey, S. F., etal. (2009). The effect of single and combined activating killer immunoglobulin-like receptor genotypes on cytomegalovirus infection and immunity after hematopoietic cell transplantation. Biol. Blood Marrow Transplant. 15, 315-325.

Conflict of Interest Statement: The authors declare that the research was conducted in the absence of any commercial or financial relationships that could be construed as a potential conflict of interest.

Received: 06 November 2012; accepted: 30 January 2013; published online: 21 February 2013.

Citation: Behrendt CE, Nakamura R, Forman SJ and Zaia JA(2013) Donor killer immunoglobulin-like receptor genes and reactivation of cytomegalovirus after HLA-matched hematopoietic stem-cell transplantation: HLA-C allotype is an essential cofactor. Front. Immun. 4:36. doi: 10.3389/fimmu.2013.00036

This article was submitted to Frontiers in NK Cell Biology, a specialty of Frontiers in Immunology.

Copyright (C) 2013 Behrendt, Nakamura, Forman and Zaia. This is an openaccess article distributed under the terms of the Creative Commons Attribution License, which permits use, distribution and reproduction in other forums, provided the original authors and source are credited and subject to any copyright notices concerning any third-party graphics etc. 